\title{
Leptospirosis in Nepal
}

\author{
Kandel N, ${ }^{1}$ Thakur GD, ${ }^{2}$ Andjaparidze $A^{1}$ \\ ${ }^{1}$ World Health Organization, Kathmandu, Nepal, ${ }^{2}$ Epidemiology and Disease Control Division, Ministry of Health and \\ Population, Nepal.
}

\section{ABSTRACT}

The study has demonstrated the evidence of leptospirosis infection in the country. It has also highlighted the challenges and the need of further researches on this disease, which seems to be under reported in the country.

Keywords: acute encephalitis syndrome; case definition; endemic; laboratory capacity leptospirosis

\section{INTRODUCTION}

Leptospirosis is a zoonotic disease, which is not regularly considered in the differential diagnosis of febrile illnesses. ${ }^{1}$ The major burden of disease is in tropical regions where diagnostic capacity is not efficiently developed. Current outbreaks, which are linked with rainfall, have raised the public profile of this zoonotic disease. ${ }^{2}$ People get this infection through contact with urine contaminated water or soil, with infected animal tissues, or from rat bites. ${ }^{3}$ Hence, farmers, miners, sewer workers, meat workers, and fishermen are at greatest risk for infection. ${ }^{4}$ It has been found that the incidence of infection is higher in warmclimate countries than in temperate regions. ${ }^{2}$

Leptospirosis infection has demonstrated wider clinical manifestation from acute febrile illnesses to hemorrhagic manifestation and in later phase it has shown the involvement of hepatic (jaundice); renal (nephritis), pulmonary (hemoptysis) and central nervous system (meningeal irritation) and sometime with cardiac arrhythmias. ${ }^{4}$ Considering the regional burden of disease and the wide range of clinical manifestation World Health Organization- South East Asia Regional Office (WHO- SEARO) has carried out consultative meeting on Leptospirosis, which has defined the case of Leptospirosis for the sensitivity of surveillance. ${ }^{5}$

India has been reporting this infection in various places of the country. ${ }^{6}$ In India, this has been a main problem with multiples epidemics in recent years associated to the monsoons and meager sanitary situations. ${ }^{7}$ In Sri Lanka the disease is hyperendemic with the annual incidence is $>140$ per million population as per the data available. $^{8}$ Some studies in Bangladesh have demonstrated frequent Leptospirosis infection among the rural population of Bangladesh. ${ }^{9}$

The frequency of Leptospirosis has not been well demonstrated in Nepal. Various outbreaks of acute

Correspondence: Dr. Nirmal Kandel, World Health Organization, Indonesia. Email: kandeln@searo.who.int 
febrile illnesses or fever of unknown origin have been reported every year in the country, however, none of these outbreaks have been so far reported with infection from Leptospirosis. Some time back in 80's there was some case studies and serological survey, which has demonstrated the Leptospirosis infection in the country. ${ }^{10}$ In addition to that, one of the studies has demonstrated one of the etiologies of acute febrile illness as Leptospirosis. ${ }^{11,12}$

\section{THE STUDY}

Nepal has been carrying out surveillance of Acute Encephalitis Syndrome (AES) since 2004 with primary focus on Japanese Encephalitis (JE). Sera and Cerebrospinal Fluid (CSF) samples have been collected for laboratory testing. In this study the samples of AES cases of 2007 and 2008, which were IgM negative for Japanese Encephalitis were used for testing of Leptospirosis. The entire tests were done by Leptotek Dri Do, BioMerieux, Netherland. This is a Latex agglutination assay, which is used to detect Leptospira specific antibodies $\lg \mathrm{M}$ and $\lg \mathrm{G}$ in human sera. ${ }^{13,14}$ This kit has sensitivity of $91 \%$ and specificity of $91 \% .{ }^{13,14}$ There were 196 and 778 JE negative AES sample of 2007 and 2008 respectively which were used for the testing. Out of these samples $37 \%$ and $43 \%$ of samples of 2007 and 2008 respectively have demonstrated IgM or IgG antibodies to Leptospirosis with given sensitivity and specificity of the kit. This result also indicates that this as ongoing infection as well as past infection.

In 2009 and 2010 there was a reporting of high number of acute febrile illnesses of unknown origin in one of the districts of the country. During the investigation it was noticed that the cases have presented with wider clinical manifestation. The samples from suspected cases were collected for various suspected etiologies for laboratory testing. The collected samples have shown mixed infection like Pandemic H1N1, Dengue fever, Falciparum Malaria and some samples have also demonstrated Leptospirosis as well. In 2010, the samples from same districts were collected during the outbreak investigation, have demonstrated Leptospirosis as a dominant infection, though other infections were also detected. In 2009, another district has reported few deaths with underlying features of AES. Few samples have been collected from suspected cases from the district and tested for different etiologies in National Public Health Laboratories. Fifty percent of these samples have demonstrated the Leptospirosis specific antibodies.
Leptospirosis is known to be endemic in India since the early 20th century..$^{6,15}$ It has been demonstrated in Bangladesh also, which occurred frequently in the rural population. ${ }^{9}$ Nepal being in similar geographical and tropical region, the country has also demonstrated Leptospirosis infection. Few studies have been carried out on this regard and there were only very few evidence of Leptospirosis in the country. ${ }^{10-12}$ This study has demonstrated evidence of Leptospirosis infection among AES morbidity and mortality. In addition to that it has been observed this infection as one of the etiology of unknown fever or acute febrile illnesses.

\section{CHALLENGES}

Due to the limitation of the laboratory capacity and existing case definition, this has been remained unnoticed since long time. At the same time this also shows the requirement of further researches; strengthening of laboratory capacity in the country for better diagnosis and revision of existing case definition that is not sensitive enough to detect the cases. With a view of this WHO-SEARO has revised the case definition and guidelines through the consultative process, which will enable to detect and report the suspected, probable and confirmed cases of Leptospirosis. ${ }^{5}$ With new case definition, better laboratory facilities, training of physicians will result timely recognition, treatment and dramatic reduction of this zoonoses in terms of morbidity and mortality.

Leptospirosis since long time has been going on in the country without any significant notice. This study and very few other studies have demonstrated the presence of infection since long time from 80's. This has shown that the disease is under reported in the country and need to carry out further studies with proper laboratory testing facilities.

\section{ACKNOWLEDGEIMENT}

We would like to acknowledge, CSR team of WHO Nepal, Surveillance Medical Officers and Mr Tika Sedai of WHO Program for Immunization Preventable Diseases, Rapid Response Teams of Epidemiology and Disease Control Division, Regional Health Directorate Central Development Region and District Public Health Offices of Chitwan and Sindhuli, National Public Health Laboratory, Professor Dr Lalit M Nath - Ex Dean of All India Institute of Medical Sciences, New Delhi, India and Disease Surveillance and Epidemiology unit of Regional Office for South East Asia for their contribution. 


\section{REFERENCES}

1. Levett PN. Leptospirosis. Clin Microbiol Rev. 2001 Apr;14(2):296-326

2. Levett PN. Leptospirosis: a forgotten zoonosis? Clin Appl Immunol Rev. 2004;4:435-48.

3. WHO. Leptospirosis worldwide, 1999. Wkly Epidemiol Rec. 1999;74:237-42.

4. Plank R, Dean D. Overview of the epidemiology, microbiology, and pathogenesis of Leptospira spp. in humans. Microbes Infect. 2000 Aug;2(10):1265-76.

5. Informal Expert consultation on Surveillance, Diagnosis and Risk Reduction of Leptospirosis; 2009 Sept 17-18; Chennai, India: World Health Organization Regional Office for South-East Asia.

6. Ratnam S, Venugopal K, Kathiravan V. Evidence of leptospiral infections in human samples in Madras city. Indian J Med Res.1987;85:516-18.

7. La Rocque RC, Breiman RF, Ari MD, Morey RE, Janan FA, Hayes JM, et al. Leptospirosis during dengue outbreak, Bangladesh. Emerg Infect Dis. 2005;11:766-9.

8. Pappas G, Papadimitriou P, Siozopoulou V, Christou L, Akritidis N. The globalization of leptospirosis: worldwide incidence trends. Int J Infect Dis. 2008;12:351-7.
9. Morshed MG, Konishi H, Terada Y, Arimitsu Y, Nakazawa T. Seroprevalence of leptospirosis in a rural flood prone district of Bangladesh. Epidemiol Infect. 1994 June;112(3):527-31.

10. Brown GW, Madasamy M, Bernthal P, Groves MG. Leptospirosis in Nepal. Trans R Soc Trop Med Hyg. 1981;75:572-3

11. Murdoch DR, Woods CW, Zimmerman MD, et al. The Etiology of Febrile Illnesses in Adults Presenting to Patan Hospital in Kathmandu. Am J Trop Med Hyg. 2004;70(6):670-5

12. Blacksell SD, Sharma NP, Phumratanaprapin W, Jenjaroen K, Peacock SJ, White NJ, et al. Serological and blood culture investigations of Nepalese fever patients. Trans R Soc Trop Med Hyg. 2007 Jul;101(7):686-90.

13. Smits HL, Chee HD, Eapen CK, Kuriakose M, Sugathan $\mathrm{S}$, Gasem $\mathrm{MH}$, et al. Latex based, rapid and easy assay for human leptospirosis in a single test format. Trop Med Int Health. 2001 Feb;6(2):114-8.

14. Biomerieux. Lepto Tek Dri Dot. [updated 2013 Mar 14] [cited 2010 Mar 1]. Available from http:/ / www.biomerieuxdiagnostics.com/servlet/srt/bio/clinical-diagnostics/ dynPage? open $=$ CNL_CLN_PRD\&doc $=$ CNL_PRD_CPL_G_ PRD_CLN_55\&pubparams.sform $=1 \&$ lang $=$ en .

15. Vijayachari P, Sugunan AP, Shriram AN. Leptospirosis: an emerging global public health problem. J Biosci. 2008 Nov;33(4):557-69. 